\title{
Article \\ Robust Sliding Mode Control of the Permanent Magnet Synchronous Motor with an Improved Power Reaching Law
}

\author{
Zhenjie Gong ${ }^{1}{ }^{(}, X$ in Ba ${ }^{1,2, *(\mathbb{C})}$, Chengning Zhang ${ }^{1}$ and Youguang Guo ${ }^{2, *(1)}$ \\ 1 National Engineering Laboratory for Electric Vehicles, Beijing Institute of Technology, Beijing 100081, China; \\ zhenjie.gong@bit.edu.cn (Z.G.); mrzhchn@bit.edu.cn (C.Z.) \\ 2 School of Electrical and Data Engineering, University of Technology Sydney, Sydney, NSW 2007, Australia \\ * Correspondence: xin.ba@bit.edu.cn (X.B.); youguang.guo-1@uts.edu.au (Y.G.)
}

Citation: Gong, Z.; Ba, X.; Zhang, C.; Guo, Y. Robust Sliding Mode Control of the Permanent Magnet Synchronous Motor with an Improved Power Reaching Law. Energies 2022, 15, 1935. https:// doi.org/10.3390/en15051935

Academic Editor: Anibal De Almeida

Received: 29 January 2022

Accepted: 2 March 2022

Published: 7 March 2022

Publisher's Note: MDPI stays neutral with regard to jurisdictional claims in published maps and institutional affiliations.

Copyright: (C) 2022 by the authors. Licensee MDPI, Basel, Switzerland. This article is an open access article distributed under the terms and conditions of the Creative Commons Attribution (CC BY) license (https:// creativecommons.org/licenses/by/ $4.0 /)$.

\begin{abstract}
To improve the suppression ability of uncertain disturbance of the sliding mode control driving system of the surface-mounted permanent magnet synchronous motor (SPMSM) and to reduce the chattering of the control output, a robust sliding mode control strategy with an improved power reaching law (IPRL) is proposed in this paper. Compared with the traditional fast power reaching law (FPRL), the IPRL incorporates the sum of the power terms of the system state variables into the conventional power terms, and uses hyperbolic tangent saturation function to replace the piecewise function, which can effectively suppress the sliding mode chattering and improve the convergence speed of the system state to the sliding mode surface. Furthermore, the robust sliding mode speed controller and sliding mode current controller of the SPMSM are designed separately with the IPRL, and detailed simulation verification is carried out to reveal the effectiveness of the IPRL. Simulation and experimental results show that compared with the FPRL, the proposed IPRL can reduce the inherent chattering phenomenon in sliding mode control, and the IPRL-based speed and current control strategy can effectively improve the dynamic performance and robustness of the system.
\end{abstract}

Keywords: permanent magnet synchronous motor; sliding mode control; chattering; robustness

\section{Introduction}

The exciting field of the permanent magnet synchronous motor (PMSM) is provided by permanent magnets, resulting in a simple structure, high power density, high efficiency, and low maintenance cost; thus, the PMSM has been widely adopted as the drive motor of electric vehicles and hybrid electric vehicles [1-3]. However, the control of PMSM has some challenges, such as coupled variables, multiple control objectives, and uncertain disturbances. In industrial applications that require a certain control accuracy range, the proportional integral (PI) control is widely used. However, the integral part of PI leads to the superposition of state errors caused by external disturbance and internal mathematical model parameter changes, which will cause integral saturation [4]. In the high-performance PMSM drive occasions, e.g., high speed and low speed/torque error requirements, the conventional PI control may be hard to trace the expected goals dynamically $[5,6]$.

To compensate for the disadvantage of the PI control of low accuracy when the motor has external and internal disturbances, several modern control algorithms have been proposed, such as fuzzy control [7], state feedback control [8], predictive control [9], model reference adaptive control [10], active disturbance rejection control [11], and variable structure control (VSC) [12]. Among them, the VSC is a special kind of nonlinear control that is manifested as a control discontinuity. The VSC can make the "structure" of the system change purposefully according to the current system state in a dynamic process. If the system state moves according to the predetermined "sliding mode" trajectory, the sliding mode VSC can be called sliding mode control (SMC) [13-15]. 
However, practical applications show that when the system state variable slides to the sliding mode surface, due to the influence of inertia and switching function, the variable will continue to reciprocate on the sliding mode surface, i.e., the chattering phenomenon occurs [16,17]. Therefore, the chattering problem of sliding mode control should be studied. In view of this, an adaptive terminal sliding mode reaching law was proposed in [18], which dynamically adopts the finite time convergence, and hence reduces the chattering in of the control system and improves the convergence rate. Ref. [19] studied a global nonsingular fixed-time terminal sliding mode control for a second-order uncertain PMSM system, which adopts a time-dependent terminal sliding surface and a piecewise continuous sliding mode control law to further improve its speed tracking performance. Ref. [20] designed an SMC design method through the differential geometric method to deal with the uncertainty nonlinear electricity generation hybrid system. To improve the dynamic response under disturbance, compared with PI, ref. [21] proposed a compound SMC controller combined with S-type function to enhance the anti-interference ability and to reduce chattering. For the study of SMC observers, ref. [22] designed a novel SMC combined with a non-homogeneous disturbance observer to eliminate chattering under disturbance and guarantee that the sliding mode state can converge to the origin. The sliding mode observer is introduced to improve the response speed of the improved nonsingular fast terminal sliding mode speed controller [23,24] added a nonlinear function to the power term of the modified direct torque control (DTC) with sliding mode controller, using the hyperbolic tangent function considering the state boundary layer to replace the traditional switching function to speed up the convergence and reduce the torque chattering. Additionally, in the DTC of the PMSM of electric vehicles, in order to reduce the overshoot of the PI control, ref. [25] designed a sliding mode torque controller and a speed controller based on the asymmetric boundary layer to replace the PI regulator. The PMSM disturbances mentioned above are all non-periodic. For the case of PMSM periodic disturbance, the adaptive sliding mode control arrangement in [26] is extended to the periodic case to suppress torque ripple using a series-structured resonant controller. Ref. [27] combined iterative learning control with SMC to enhance the PMSM system robustness and suppress chattering by adopting the adaptive algorithms.

In this paper, an SMC with an improved power reaching law (IPRL) is proposed, and it is embedded in the speed loop and the current loop of the field-oriented control (FOC) system of the PMSM to improve the control performance, such as obtaining the reference $d$ and $q$-axis current and voltage accurately, reducing torque ripple, and improving the speed dynamic response. The main contributions of this paper can be concluded as follows:

1. An improved power reaching law with hyperbolic tangent saturation function and the PMSM system state variable is developed, and it can boost the sliding mode reaching speed while keeping the chattering within a certain range. Therefore, the chattering of the PMSM system can be constructively suppressed and the speed/torque tracking performance can be advantageously improved.

2. A sliding mode speed controller (SMSC) and a sliding mode current controller (SMCC) with the IPRL of the PMSM are designed, which can effectively reduce torque and current ripples, and boost speed response and anti-disturbance ability.

The remainder of this paper is organized as follows. Section 2 introduces the design process of the proposed IPRL and presents the design of SMSC and SMCC with the IPRL. Section 3 depicts the detailed simulation and experimental verification, while the conclusions and discussions are made in Section 4.

\section{Design of the Sliding Mode Controller}

2.1. The Improved Sliding Mode Reaching Law

The fast power reaching law (FPRL) [28] is as follows:

$$
\dot{s}=-\varepsilon|s|^{\alpha} \operatorname{sgn}(s)-k s
$$


where $s$ is the sliding mode surface, while $\varepsilon$ and $k$ are positive constants.

By adjusting the value of $\varepsilon$, it can be ensured that when the system state is far from the sliding mode dynamics, Equation (1) can guarantee that the system state tends to the sliding mode dynamics at a higher speed. When the system state tends to the sliding mode, the power term $\varepsilon|s|^{\alpha}$ can ensure a small control gain to reduce chattering.

To avoid the rapid switching of positive and negative values of symbolic function $\operatorname{sgn}(s)$ at $s=0$, the $\operatorname{sgn}(s)$ function can be modified as the saturation function which is smoother at $s=0$. Substitute the conventional symbolic function $\operatorname{sgn}(s)$ with the hyperbolic tangent saturation function, and the boundary layer thickness is further designed as controllable and adjustable, and then the hyperbolic tangent saturation function combined with the design of the boundary layer thickness is able to improve the quality of system switching at $s=0$. Therefore, the sliding mode variable is continuous at the sliding mode surface $s=0$, which is helpful to inhibit the influence of chattering.

The segmented hyperbolic tangent saturation function $H(s)$ with adjustable boundary layer $\delta$ is expressed as:

$$
\mathrm{H}(\mathrm{s})= \begin{cases}\operatorname{sgn}(\mathrm{s}) & |\mathrm{s}| \geq \delta \\ \tanh (\mu \mathrm{s}) & |\mathrm{s}|<\delta\end{cases}
$$

where $\mu=\pi \delta$, and $\delta$ is the thickness of the boundary layer. The setting of $\delta$ will affect the amplitude of chattering. A larger value of $\delta$ can improve the system adaptability to disturbances. However, the increasing $\delta$ will decrease the system response speed.

The improved power reaching law (IPRL) can be designed as:

$$
\dot{s}=-\varepsilon|s|^{\alpha} H(s)-k|x|^{\beta} s
$$

where $0<\alpha<1, \beta>0, \varepsilon>0$ and $k>0$. $s$ represents the sliding mode surface, $x$ is the system state variable, $\varepsilon$ is the switching gain and $k$ is a linear gain.

Compared with the conventional FPRL, the reaching speed of the SPMSM control system with the NPRL realizes the adaptive changes according to the system states and sliding mode surface. When the system states at the beginning of the approaching motion, the reaching speed of the NPRL is remarkably fast, while when the system states close to the sliding mode surface, the reaching speed slowly decreases and eventually becomes zero.

\subsection{Design of the Sliding Mode Speed Controller (SMSC)}

Inevitably, the model parameters of the PMSM are changing during operation, causing the motor speed to deviate from the reference value. Moreover, sudden increase or decrease of the motor load can also cause motor speed ripple. The aim of designing the SMSC should be to maintain the actual motor speed $\omega$ to accurately track the reference speed $\omega_{\text {ref }}$ at any time. Therefore, the speed tracking error can be selected as the performance evaluation indicator, i.e., state variable associated with the approaching speed when designing the SMSC, and then it can be calculated as:

$$
e_{\omega}=\omega_{r e f}-\omega
$$

where $e_{\omega}$ is the speed tracking error.

The design the SMSC includes two steps: establishing a suitable sliding mode switching surface, and developing an appropriate output control of sliding mode control based on the IPRL.

The suitable sliding mode surface can be set as:

$$
\mathrm{s}_{\omega}=\mathrm{e}_{\omega}
$$

The mathematical movement equation of the SPMSM can be written as:

$$
\dot{\omega}=\frac{1}{J}\left(T_{e}-T_{L}-D \omega\right)
$$


where $J, \omega, T_{e}, T_{L}$ and $D$ are the moment of inertia, angular speed, electromagnetic torque, load torque and damping coefficient, respectively.

Taking derivatives of both sides of Equation (5), one obtains:

$$
\dot{s}_{\omega}=\dot{\omega}_{r e f}-\dot{\omega}=\dot{\omega}_{r e f}-\frac{1}{J}\left(T_{e}-T_{L}-D \omega\right)
$$

Incorporating (3) into (7), one can obtain:

$$
-\varepsilon\left|s_{\omega}\right|^{\alpha} H\left(s_{\omega}\right)-k\left|x_{\omega}\right|^{\beta} s_{\omega}=\dot{\omega}_{r e f}-\frac{1}{J}\left(T_{e}-T_{L}-D \omega\right)
$$

The electromagnetic torque of the SPMSM can be calculated as:

$$
T_{e}=\frac{3}{2} i_{q} \lambda_{f}
$$

where $T_{e}$ is the electromagnetic torque, $i_{q}$ the $q$-axis current and $\lambda_{f}$ the flux linkage of permanent magnets.

Hence, the output of the SMSC, or the reference $q$-axis current $i_{\text {qref }}$ of the FOC system can be organized as:

$$
i_{\text {qref }}=\frac{2}{3 \lambda_{f}}\left(J \dot{\omega}_{r e f}+T_{L}+D \omega+\varepsilon J\left|s_{\omega}\right|^{\alpha} H\left(s_{\omega}\right)+k J\left|x_{\omega}\right|^{\beta} s_{\omega}\right)
$$

\subsection{Design of the Sliding Mode Current Controller (SMCC)}

The current equations of SPMSM are given as follows:

$$
\left\{\begin{array}{l}
\dot{i}_{d}=-\frac{R}{L} i_{d}+\frac{1}{L} u_{d}+\omega_{e} i_{q} \\
\dot{i}_{q}=-\frac{R}{L} i_{q}+\frac{1}{L} u_{q}-\omega_{e} i_{d}-\frac{1}{L} \omega_{e} \lambda_{f}
\end{array}\right.
$$

where $u_{d}$ and $u_{q}$ are the $d$ - and $q$-axis stator voltages, and $i_{d}$ and $i_{q}$ are the $d$ - and $q$-axis currents. $L$ is the inductance, $R$ is the stator resistance, and $\omega_{e}$ is the angular velocity.

The proposed SMCC should maintain the actual motor $d$ - and $q$-axis currents $i_{d}$ and $i_{q}$ to accurately track the reference current $i_{\text {dref }}=0$ and $i_{\text {qref }}$ at any time against any mathematical model parameter perturbation, such as resistance variation $\Delta R$, inductance variation $\Delta L$ and permanent magnetic flux linkage variation $\Delta \lambda_{f}$. To realize this goal, the current tracking errors are defined as:

$$
\left\{\begin{array}{l}
e_{d}=i_{\text {dref }}-i_{d} \\
e_{q}=i_{\text {qref }}-i_{q}
\end{array}\right.
$$

The current sliding mode surfaces can be set as:

$$
\left\{\begin{array}{l}
s_{d}=e_{d} \\
s_{q}=e_{q}
\end{array}\right.
$$

Taking derivatives of both sides of Equation (13), the following equations are obtained:

$$
\left\{\begin{array}{l}
\dot{s}_{d}=\dot{i}_{\text {dref }}-\dot{i}_{d}=\dot{i}_{\text {dref }}+\frac{R}{L} i_{d}-\frac{1}{L} u_{d}-\omega_{e} i_{q} \\
\dot{s}_{q}=\dot{i}_{\text {qref }}-\dot{i}_{q}=\dot{i}_{\text {qref }}+\frac{R}{L} i_{q}-\frac{1}{L} u_{q}+\omega_{e} i_{d}+\frac{1}{L} \omega_{e} \lambda_{f}
\end{array}\right.
$$

Incorporating Equation (3) into Equation (14), one can obtain:

$$
\left\{\begin{aligned}
-\varepsilon\left|s_{d}\right|^{\alpha} H\left(s_{d}\right)-k\left|x_{d}\right|^{\beta} s_{d} & =\dot{i}_{\text {dref }}+\frac{R}{L} i_{d}-\frac{1}{L} u_{d}-\omega_{e} i_{q} \\
-\varepsilon\left|s_{q}\right|^{\alpha} H\left(s_{q}\right)-k\left|x_{q}\right|^{\beta} s_{q} & =\dot{i}_{q r e f}+\frac{R}{L} i_{q}-\frac{1}{L} u_{q}+\omega_{e} i_{d}+\frac{1}{L} \omega_{e} \lambda_{f}
\end{aligned}\right.
$$


Hence, the output of the SMCC, or the reference $d$ - and $q$-axis voltage $u_{d r e f}$ and $u_{\text {qref }}$ can be organized as:

$$
\left\{\begin{array}{l}
u_{\text {dref }}=L \dot{i}_{\text {dref }}+R i_{d}-L \omega_{e} i_{q}+\varepsilon L\left|s_{d}\right|^{\alpha} H\left(s_{d}\right)+k L\left|x_{d}\right|^{\beta} s_{d} \\
u_{\text {qref }}=L \dot{i}_{\text {qref }}+R i_{q}+L \omega_{e} i_{d}+\omega_{e} \lambda_{f}+\varepsilon L\left|s_{q}\right|^{\alpha} H\left(s_{q}\right)+k L\left|x_{q}\right|^{\beta} s_{q}
\end{array}\right.
$$

\subsection{Proof of the Stability}

To verify the stability of the improved SMSC and current controller, the Lyapunov function is selected as $V=s^{2} / 2$. To satisfy the sliding mode arrival condition, the following equation should be established.

$$
\dot{V}=s \dot{S} \leq 0
$$

Combining Equations (3), (5), (13) and (17), one has:

$$
\dot{V}=s \dot{S}=s\left[-\varepsilon|s|^{\alpha} H(s)-k|x|^{\beta} s\right]
$$

Substituting Equation (2) into Equation (18), one can obtain:

$$
\dot{V}=\left\{\begin{array}{cc}
-\varepsilon|s|^{\alpha+1}-k|x|^{\beta} s^{2} & |s| \geq \delta \\
-\varepsilon|s|^{\alpha+1}|\tanh (s)|-k|x|^{\beta} s^{2} & |s|<\delta
\end{array}\right.
$$

In Equation (19), $\varepsilon$ and $k$ are positive, while $|s| \geq 0$ and $|x| \geq 0$. Therefore, the first derivative of the Lyapunov function is always less than or equal to zero, i.e., the stability of the improved SMSC and SMCC can be guaranteed.

\section{Simulation and Experimental Verification}

To further observe the performance of the proposed SMSC and SMCC, a prototype of SPMSM is investigated, and the mathematical model parameters of the SPMSM are presented in Table 1. To make the most use of the winding current to generate the electromagnetic torque, maximum torque per ampere control strategies of the SPMSM, i.e., $i_{d}=0$, is constructed on Matlab/Simulink and experimental platform, respectively. The segmented hyperbolic tangent saturation function $H(s)$ simulation parameters are set as follows: $\varepsilon=10, k=200, \alpha=0.5, \beta=1.5$ and $\delta=1$.

Table 1. Parameters of the SPMSM.

\begin{tabular}{ccc}
\hline Symbol & Parameter & Value \\
\hline$P$ & Number of pole pairs & 4 \\
\hline$R$ & Stator resistance $(\Omega)$ & 0.365 \\
\hline$L=L_{d}=L_{q}$ & Stator inductance $(\mathrm{mH})$ & 0.1225 \\
$\lambda_{f}$ & Rotor flux linkage $(\mathrm{Wb})$ & 0.1667 \\
$J$ & Rotational inertia $\left(\mathrm{kg} \cdot \mathrm{m}^{2}\right)$ & 0.00197 \\
$D$ & Damping Coefficient $(\mathrm{Nms})$ & 0.001 \\
\hline
\end{tabular}

\subsection{Comparison of the FPRL and IPRL}

A comparison of the FPRL and IPRL in terms of the reaching time is presented according to mathematical analysis. The typical motor controlled system is shown as:

$$
\ddot{\theta}(t)=-f(\theta, t)+b u(t)+d(t)
$$

where $u(t)$ represents the controller input, $\theta(t)$ the position instruction, while $d(t)$ is the external disturbance, and $d(t) \leq \mathrm{D} \cdot f(\theta, t)=25 \dot{\theta}, b=133$, and command position signal satisfies $\theta_{\mathrm{d}}(t)=\sin (\mathrm{t})$. 
Assume that the sliding mode function can be computed as:

$$
s(t)=c e(t)+\dot{e}(t)
$$

where $e(t)=\theta_{\mathrm{d}}(t)-\theta(t)$ denotes the tracking error, and $\dot{e}(t)=\dot{\theta}_{\mathrm{d}}(t)-\dot{\theta}(t)$.

Taking derivatives of both side of Equation (21), one obtains:

$$
\begin{aligned}
\dot{s}(t) & =c \dot{e}(t)+\ddot{e}(t) \\
& =c\left(\dot{\theta}_{d}(t)-\dot{\theta}(t)\right)+\left(\ddot{\theta}_{d}(t)+f(\theta, t)-b u(t)-d(t)\right)
\end{aligned}
$$

Considering the sliding mode reaching law of FPRL in Equation (1) and IPRL in Equation (3), the sliding mode controller input are as follows:

$$
\begin{gathered}
u_{F P R L}(t)=\frac{1}{b}\left(-\varepsilon|s|^{\alpha} \operatorname{sgn}(s)-k s+c\left(\dot{\theta}_{d}(t)-\dot{\theta}(t)\right)+\ddot{\theta}_{d}(t)+f(\theta, t)\right) \\
u_{I P R L}(t)=\frac{1}{b}\left(-\varepsilon|s|^{\alpha} H(s)-k|x|^{\beta} s+c\left(\dot{\theta}_{d}(t)-\dot{\theta}(t)\right)+\ddot{\theta}_{d}(t)+f(\theta, t)\right)
\end{gathered}
$$

where Equation (23) denotes the FPRL controller input, and Equation (24) is the IPRL controller input.

The simulations are carried out among FPRL and IPRL using MATLAB s-function. The simulation parameters are set as follows: $\varepsilon=10, k=200, \alpha=0.5$, and $\beta=1.5$. The ideal position signal $\theta_{\mathrm{d}}$ is set as $\sin (t)$. The controlled object $x(0)$ is set as $\left[x_{1}, x_{2}\right]=[-1.5,-1.5]$. $x_{1}$ and $x_{2}$ denote the initial value of the position instruction $\theta$ and its first derivative $\dot{\theta}$, respectively.

Figure 1 shows the performance comparison between FPRL and IPRL. It is seen that the IPRL has significantly better performance than the FPRL in both position tracking of the reference signal and suppressing the chattering. Compared with FPRL, the proposed IPRL has faster arrival speed and better output performance. These advantages will be further verified in the following simulations and experiments.

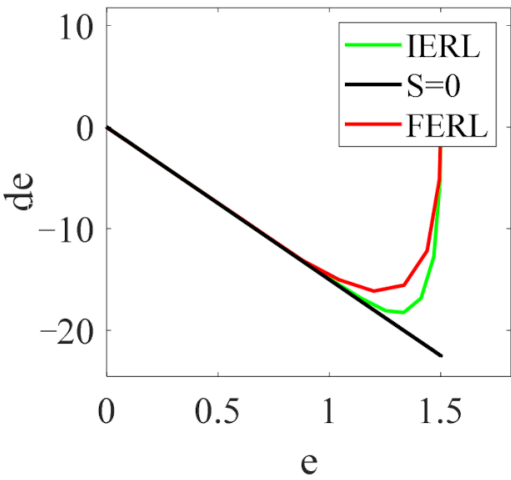

(a)

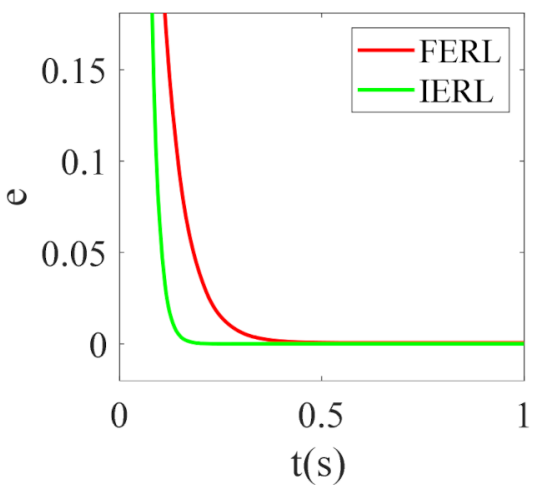

(b)

Figure 1. Performance comparison results of FPRL and IPRL: (a) Phase trajectory; (b) Error convergence rate.

\subsection{Simulation Verification}

The simulation block diagram of the FOC system with the SMSC and SMCC of the PMSM is shown in Figure 2. 


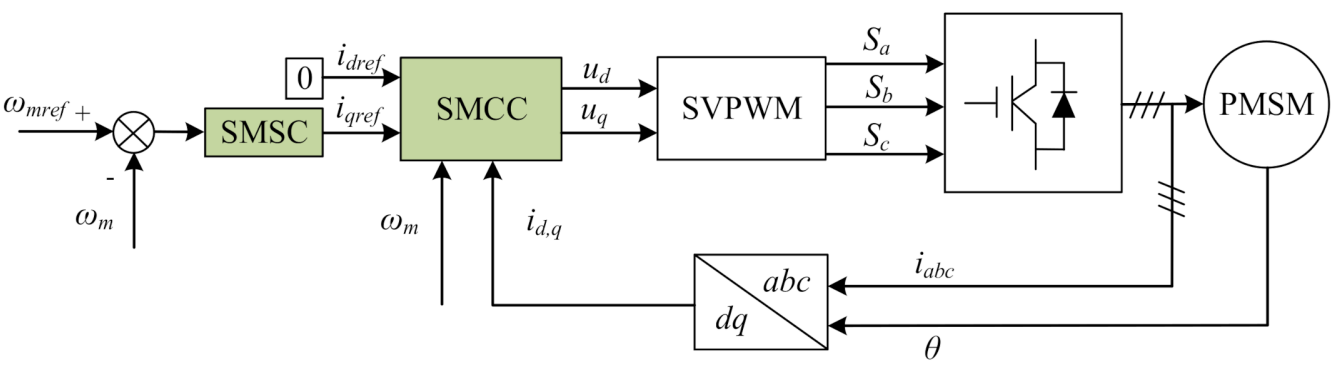

Figure 2. Block diagram of the FOC system with the SMSC and SMCC of the PMSM.

Figures 3-5 compare the simulation results of the PMSM SMC system between the FPRL and IPRL. As shown by the speed response curves in Figure 3, the response time of the traditional SMC system with the FPRL is $0.025 \mathrm{~s}$, while that of the proposed SMC system with the IPRL is $0.0125 \mathrm{~s}$. It is noted that the proposed SMC system with the IPRL accelerates the speed response of the PMSM.

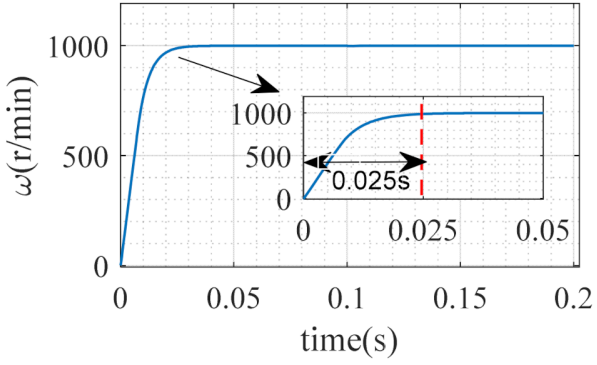

(a)

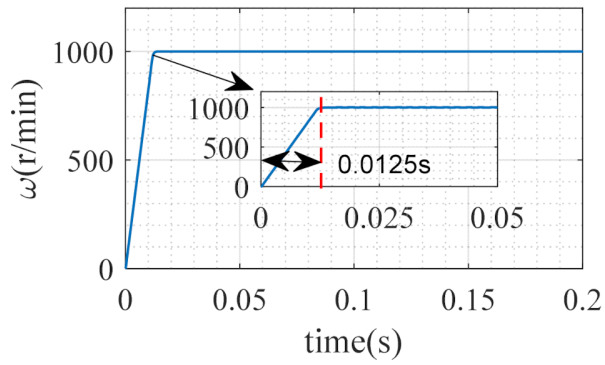

(b)

Figure 3. Speed response: (a) SMC system with the FPRL; (b) SMC system with the IPRL.

Set the desired speed of the PMSM to $1000 \mathrm{r} / \mathrm{min}$ and the load torque to $3 \mathrm{Nm}$ at the starting state, and the load torque changes from $3 \mathrm{Nm}$ to $9 \mathrm{Nm}$ at $0.1 \mathrm{~s}$, and then to $5 \mathrm{Nm}$ at $0.15 \mathrm{~s}$. The speed response comparison results during the above condition are illustrated in Figure 4, and the speed fluctuation between two different loads of these two SMC control strategies are $\Delta \omega=4$ and $\Delta \omega=0.5 \mathrm{r} / \mathrm{min}$, respectively. Therefore, the proposed method has better speed robustness.

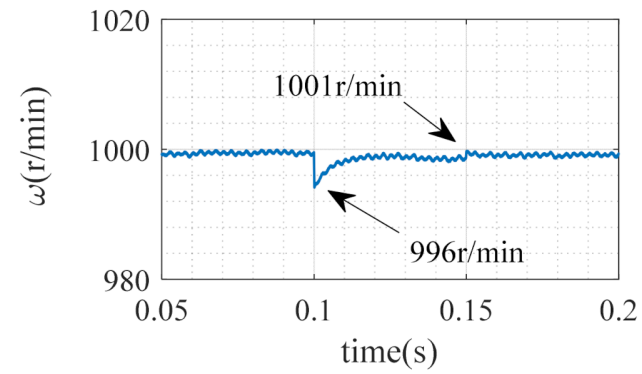

(a)

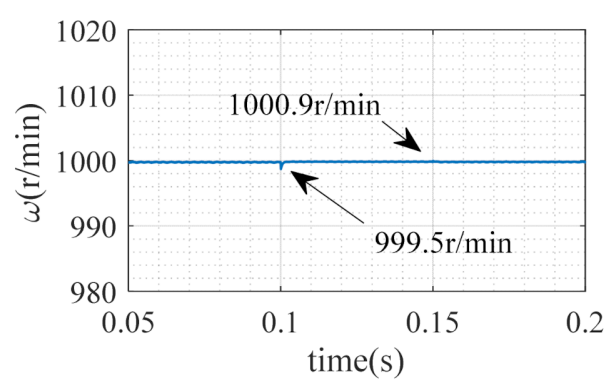

(b)

Figure 4. Speed response when the load torque changes: (a) SMC system with the FPRL; (b) SMC system with the IPRL.

Figure 5 describes the torque response during the load change conditions. The torque ripple range of the traditional SMC system with the FPRL is approximately $1.65 \mathrm{Nm}$, as shown in Figure 5a, while that of the proposed SMC system with the IPRL is $0.7 \mathrm{Nm}$, which has been significantly reduced, as shown in Figure $5 b$. 


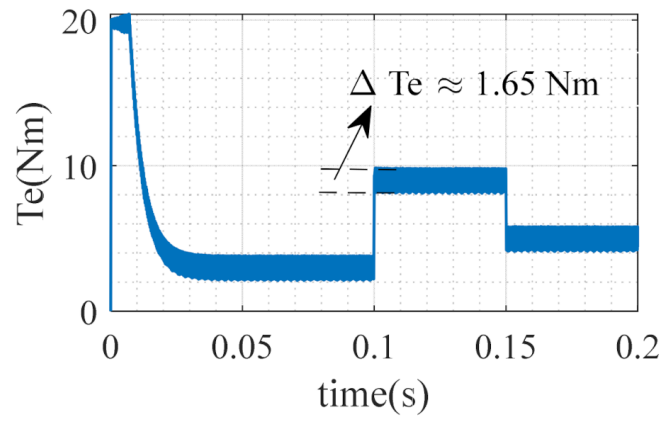

(a)

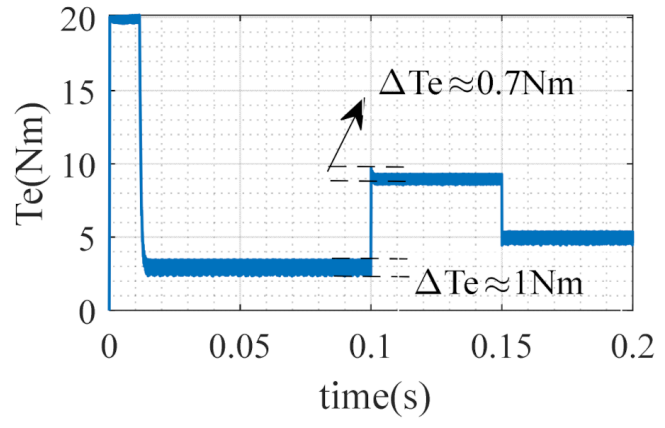

(b)

Figure 5. Torque response: (a) SMC system with the FPRL; (b) SMC system with the IPRL.

To further verify the effectiveness of the proposed SMC system with the IPRL, parameter mismatch simulation results are presented in Figure 6. Set the motor parameters to $R^{\prime}=2 R, L^{\prime}=1.2 L$ and $\lambda_{f}^{\prime}=0.8 \lambda_{f}$, taking into account the variation range of the motor's stator resistance, inductance and permanent magnet flux linkage during operation [29]. Figure 6 shows that the $q$-axis current pulsation of the proposed SMC system with the IPRL, as shown in Figure $6 \mathrm{~b}$, is about $0.7 \mathrm{~A}$, which is half of the q-axis current pulsation of the traditional ones, as shown in Figure 6a. In other words, the proposed SMC system with the IPRL has excellent anti-disturbance ability.

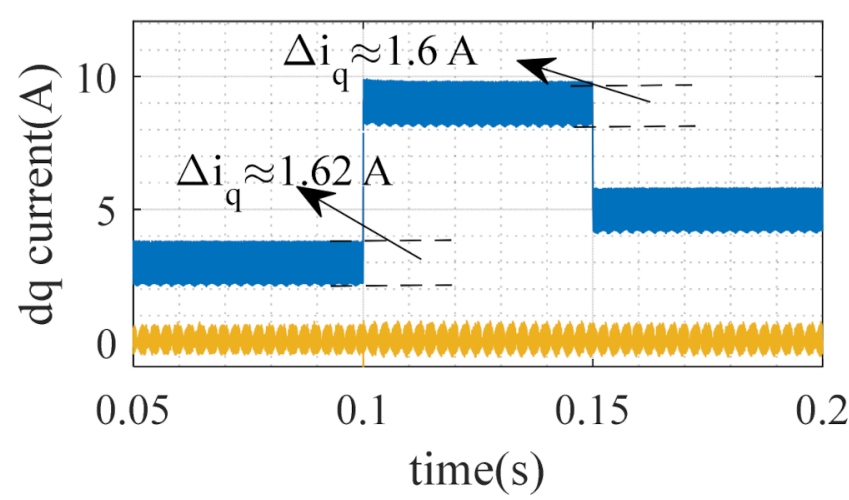

(a)

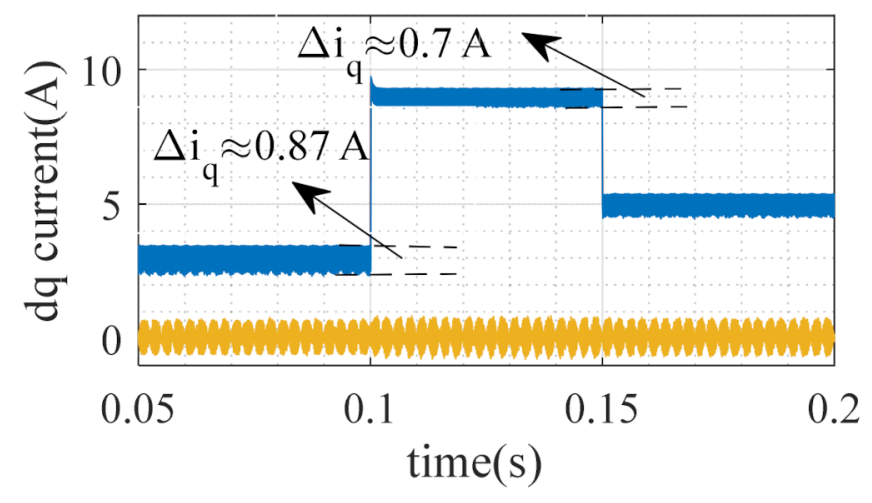

(b)

Figure 6. $d$ - and $q$-axis current response: (a) SMC system with the FPRL; (b) SMC system with the IPRL.

Figures 3, 4, 5 and 6 show that in the proposed SMC system with the IPRL, both the speed and current of the PMSM have a fast response and small steady-state error, and the proposed system can maintain good adaptability and robustness when the parameters of the motor mathematical model change or load torque changes.

\subsection{Experimental Verification}

The effectiveness of the proposed SMSC and SMCC has been validated by simulations. To further verify the superiority of the SMC strategy with the IPRL, a comparative experimental analysis is carried out. The PMSM model parameters and SMC parameters in the experimental cases are the same as the simulation parameters as listed in Table 1. Figure 7 shows the experimental platform of the PMSM system, and a load motor is connected via a torque/speed transducer while the PMSM prototype is operated as a motor. 


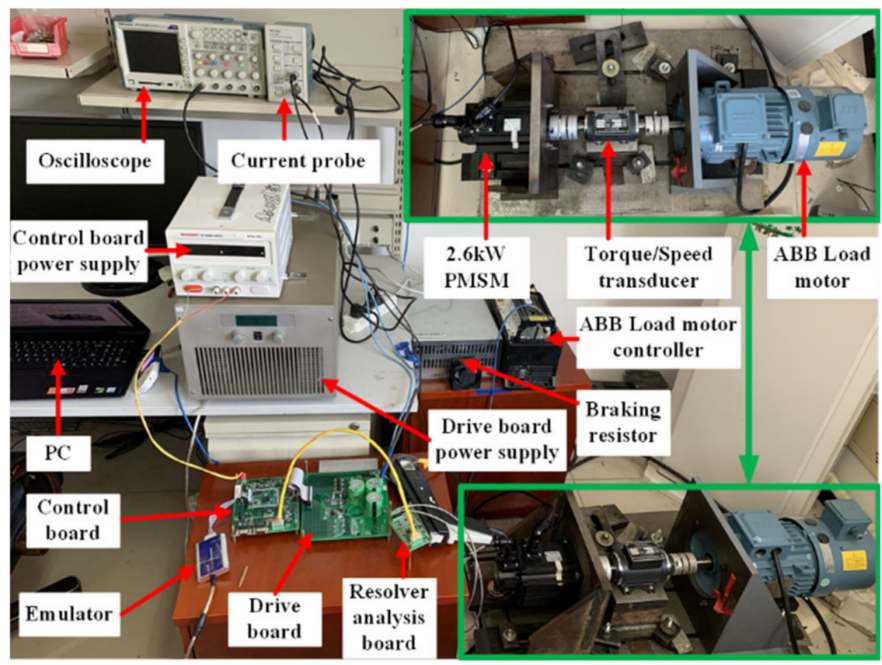

Figure 7. Experimental platform of the PMSM system.

The platform's main sensor acquisitions and motor drive equipment include:

(a) Torque/speed transducer which connects the SPMSM and ABB load motor, and it is used to collect and display the motor speed and torque;

(b) The resolver analysis board is a bridge between the control board and the resolver in the SPMSM. To be more specific, the outputs of the resolver are analog signals, which are transformed into digital signals via the resolver analysis board;

(c) Control board is the heart of the SPMSM driven system. The primary function is to process and analyze the three-phase current signals, the DC bus voltage signal, and the digital quantity obtained by the resolver board, and then generate the required six PWM signals to the drive board.

(d) Isolated emulator XDS200, which is the connection between the control board and PC. It is able to transmit information between the PC and the control board bidirectionally.

Set the reference speed to $1000 \mathrm{r} / \mathrm{min}$ when the motor is stationary and the reference load torque is $4 \mathrm{Nm}$, and then the load torque increases to $8 \mathrm{Nm}$ at $1.5 \mathrm{~s}$. Figure 8 shows the torque and speed responses of the SMC system with the FPRL and IPRL. In the SMC system with the conventional FPRL, the fluctuations of torque and speed are approximately equal to $1 \mathrm{Nm}$ and $0.25 \mathrm{r} / \mathrm{min}$, respectively, as shown in Figure 8a. However, in the proposed SMC system with the IPRL, they are respectively near $0.4 \mathrm{Nm}$ and $0.2 \mathrm{r} / \mathrm{min}$, which have been remarkably weakened, as shown in Figure 8b.

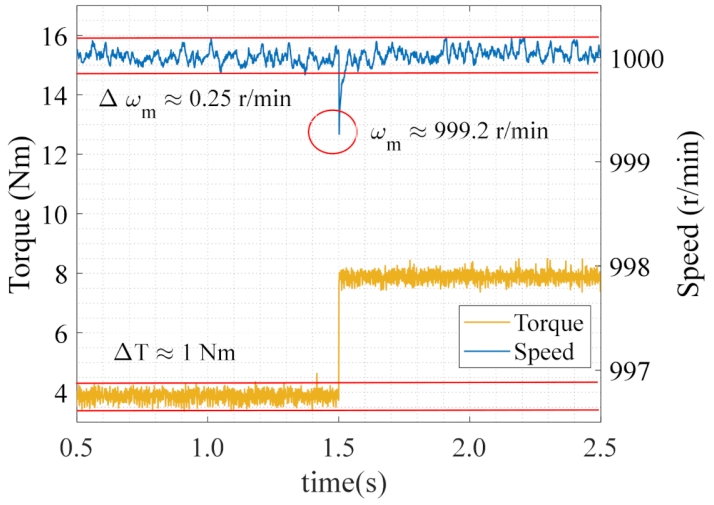

(a)

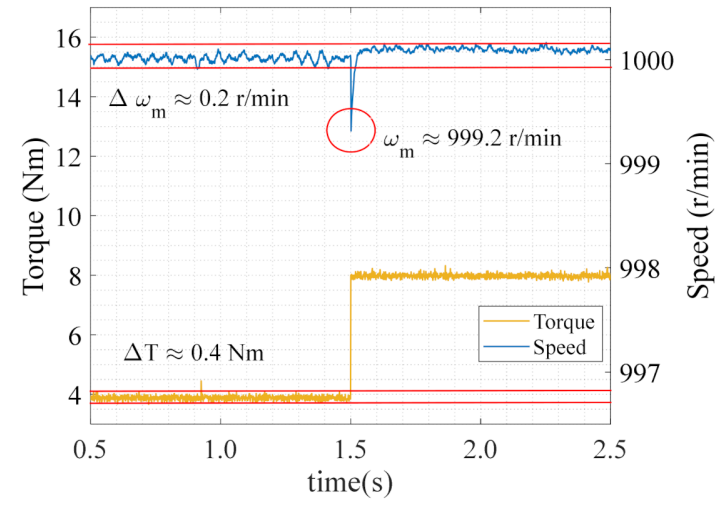

(b)

Figure 8. The torque and speed response: (a) SMC system with the FPRL; (b) SMC system with the IPRL. 
To verify the steady-state characteristics of the two SMC control methods under multiple speed and torque conditions, set the reference speeds of the PMSM vary from 0 to $1200 \mathrm{r} / \mathrm{min}$, while the reference torques change from $2 \mathrm{Nm}$ to $10 \mathrm{Nm}$, and the torque/speed transducer is adopted to collect actual torque and speed of the motor. The errors between the reference speeds/torques and actual speeds/torques are evaluated via the standard deviation, and the standard deviation is calculated as:

$$
\sigma=\sqrt{\frac{1}{N} \sum_{i=1}^{N}\left(x_{i}-\bar{x}\right)^{2}}
$$

where

$$
\bar{x}=\frac{1}{N} \sum_{i=1}^{N} x_{i}
$$

Figure 9 illustrates the contour maps of the speed standard deviation of two SMC systems with different reaching laws. As shown in Figure 9a, the SMC control strategy with FPRL, the experimental standard deviation of the speed is lower than 0.1 when the motor speed is higher than $300 \mathrm{r} / \mathrm{min}$ during the full torque range. When the speed is lower than $200 \mathrm{r} / \mathrm{min}$, the actual speed presents a larger deviation range, especially under medium to high torque loads. The speed standard deviation drops sharply with the increase of the speed, and it reaches a maximum of more than 0.25 when the PMSM is operating at low speed.

Figure $9 \mathrm{~b}$ presents the speed standard deviation of the proposed SMC system with the IPRL. The speed standard deviation $\sigma_{\text {speed }}$ is lower than 0.08 during the overall speed and torque ranges. Additionally, more than $95 \%$ of the contour map suggests that the speed standard deviations are less than 0.04 . In the high speed range of $1100-1200 \mathrm{r} / \mathrm{min}$ and the load torque of $1 \mathrm{Nm}, \sigma_{\text {speed }}$ reaches the highest value of 0.08 . It can be seen from the comparison of the experimental results that compared with the traditional FPRL, the proposed IPRL can effectively reduce the speed pulsation, i.e., the speed loop adopting IPRL control strategy has the superiority of speed stability.

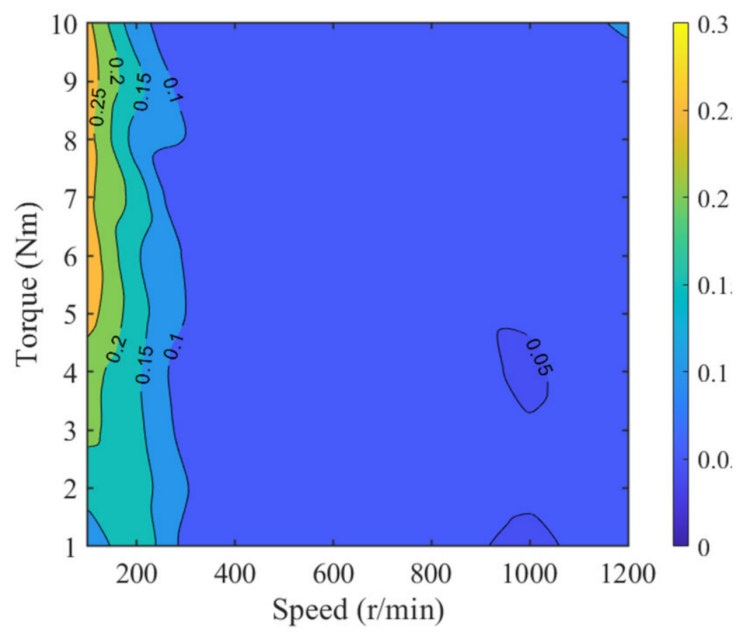

(a)

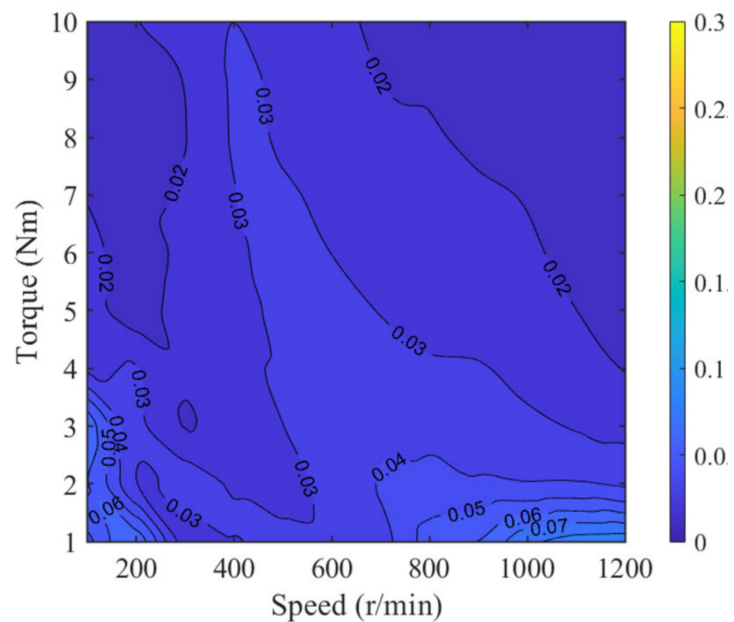

(b)

Figure 9. The speed standard deviation: (a) SMC system with the FPRL; (b) SMC system with the IPRL.

Figure 10 illustrates the contour maps of electromagnetic torque standard deviation in the same working conditions. It can be seen from Figure 10a that in the traditional SMC system with the FPRL, the torque standard deviation $\sigma_{\text {torque }}$ increases as the motor speed increases, and the $\sigma_{\text {torque }}$ varies from 0.1 to 0.5 . On the contrary, in the proposed SMC system 
with the IPRL, as shown in Figure 10b, electromagnetic torque ripple can be effectively suppressed. The average value of $\sigma_{\text {torque }}$ is below 0.25 . In the surface-mounted PMSM, the electromagnetic torque can be considered proportional to the $q$-axis current when the PM flux is assumed to be constant. Therefore, Figure 10 can also reflect the pulsation of the $q$-axis current, and it suggests that the harmonics of the three-phase current in the proposed method have been dramatically reduced. Furthermore, the proposed SMCC with the IPRL improves the performance of the current loop.

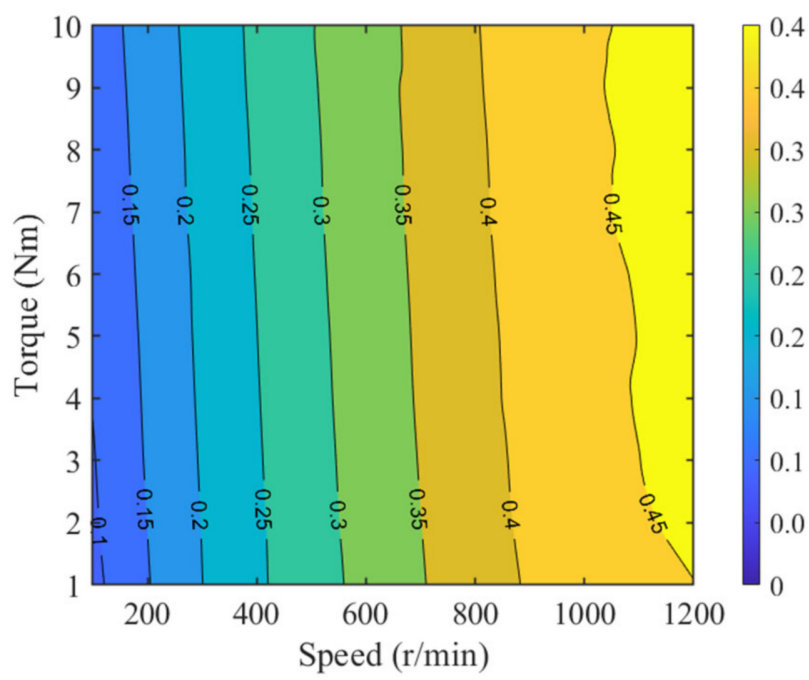

(a)

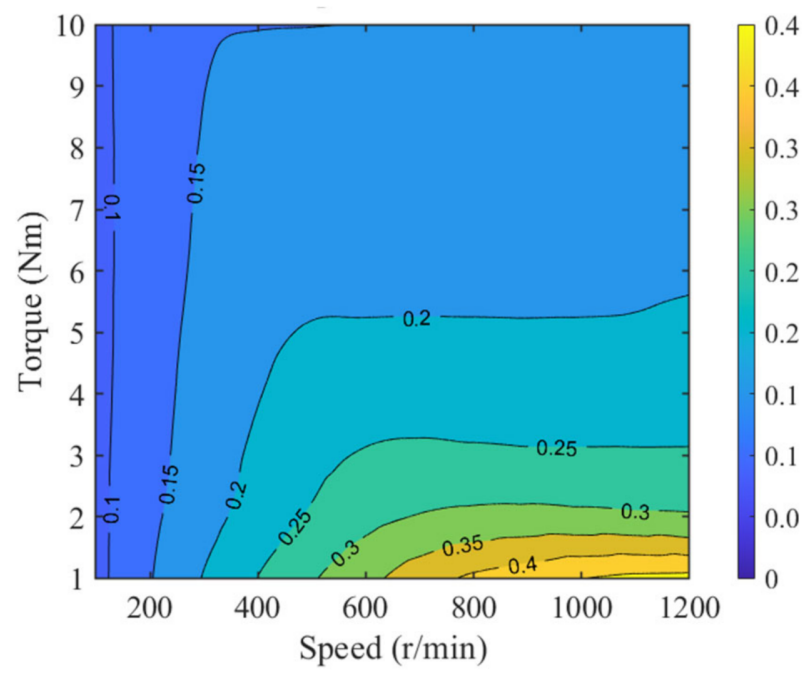

(b)

Figure 10. The electromagnetic torque standard deviation: (a) SMC system with the FPRL; (b) SMC system with the IPRL.

\section{Conclusions}

This paper presented a robust sliding mode control of the PMSM with an improved power reaching law. The improved power reaching law is able to effectively reduce the chattering of the control system and improve the convergence speed of the state variables, and this performance was verified by simulations. Accordingly, a sliding mode speed controller and a sliding mode current controller with the IPRL of the PMSM were designed. A series of simulations suggested that, compared with the traditional SMC system with the FPRL of the PMSM, the proposed SMC system with the IPRL can accelerate the speed response and reduce the torque ripple when the load changes; moreover, it shows better speed and current robustness when the load changes or parameters mismatch. Finally, bench experiments of SPMSM are carried out, and the proposed SMC system with the IPRL demonstrates excellent accuracy in tracking the reference speeds and torques over the whole operating range.

PMSM is often used as a drive motor for electric vehicles, electric aircraft, etc. The driving conditions of the vehicle are complex and changeable. The proposed low torque ripple SMC control scheme is feasible for the torque control requirements of vehicle dynamic driving and stable driving under uncertain road load conditions. Electric aircraft have a wide range of temperature changes, which cause the internal model parameters of the motor to change. In addition, there is much aircraft vibration and electromagnetic interference, so it is of certain significance to use SMC with strong anti-interference ability.

Author Contributions: Conceptualization, Z.G., X.B., C.Z. and Y.G.; methodology, Z.G. and X.B.; software, Z.G.; validation, C.Z. and Y.G.; formal analysis, X.B. and Y.G.; investigation, C.Z.; resources, Z.G.; data curation, Z.G.; writing-original draft preparation, Z.G. and X.B.; writing-review and editing, Y.G. and C.Z.; visualization, Z.G.; supervision, C.Z. and Y.G.; project administration, X.B. and 
Y.G.; funding acquisition, X.B. and C.Z. All authors have read and agreed to the published version of the manuscript.

Funding: This research was funded by key Areas of Guangdong Province under the Project Name: Integration and industrialization of high performance, long endurance and integrated electric drive system, Grant Number 2019B090910001.

Data Availability Statement: Not applicable.

Conflicts of Interest: The authors declare no conflict of interest.

\section{References}

1. Wang, Y.; Feng, Y.; Zhang, X.; Liang, J.; Cheng, X. New Reaching Law Control for Permanent Magnet Synchronous Motor with Extended Disturbance Observer. IEEE Access 2019, 7, 186296-186307. [CrossRef]

2. Sain, C.; Biswas, P.K.; Satpathy, P.R.; Babu, T.S.; Alhelou, H.H. Self-Controlled PMSM drive employed in light electric vehicledynamic strategy and performance optimization. IEEE Access 2021, 9, 57967-57975. [CrossRef]

3. Hosseinzadeh, M.; Salmasi, F.R. Analysis and detection of a wind system failure in a micro-grid. J. Renew. Sustain. Energy 2016, 8, 043302. [CrossRef]

4. Zhong, Y.; Huang, S.; Luo, D. Stabilization and Speed Control of a Permanent Magnet Synchronous Motor with Dual-Rotating Rotors. Energies 2018, 11, 2786. [CrossRef]

5. Zhang, X.; Zhao, K.; Su, L. A PMSM Sliding Mode Control System Based on a Novel Reaching Law. In Proceedings of the 2011 International Conference on Electrical Machines and Systems, Beijing, China, 20-23 August 2011.

6. Liang, D.; Li, J.; Qu, R. Sensorless Control of Permanent Magnet Synchronous Machine Based on Second-Order Sliding-Mode Observer with Online Resistance Estimation. IEEE Trans. Ind. Appl. 2017, 53, 3672-3682. [CrossRef]

7. Kung, Y.S.; Tsai, M.H. FPGA-Based Speed Control IC for PMSM Drive with Adaptive Fuzzy Control. IEEE Trans. Power Electron. 2007, 22, 2476-2486. [CrossRef]

8. Sun, X.; Hu, C.; Lei, G.; Guo, Y.G.; Zhu, J.G. State Feedback Control for a PM Hub Motor Based on Gray Wolf Optimization Algorithm. IEEE Trans. Power Electron. 2020, 35, 1136-1146. [CrossRef]

9. Ba, X.; Wang, P.; Zhang, C.N.; Zhu, J.G.; Guo, Y.G. Improved Deadbeat Predictive Current Control to Enhance the Performance of the Drive System of Permanent Magnet Synchronous Motors. IEEE Trans. Appl. Supercond. 2021, 31, 0603004. [CrossRef]

10. Rao, G.M.; Babu, M.S.; Ram, B.V.S. Supervisory Performances of PMSM Using Model Reference Adaptive Control. In Proceedings of the 2016 International Conference on Signal Processing, Communication, Power and Embedded System (SCOPES), Paralakhemundi, India, 3-5 October 2016.

11. Li, Y.; Chen, Y. Active Disturbance Rejection Control for Permanent Magnet Synchronous Motor with Noise: Analysis of Parameter Characteristics of Extended State Observer. In Proceedings of the 40th Chinese Control Conference (CCC), Shanghai, China, 26-28 July 2021.

12. Repecho, V.; Biel, D.; Arias, A. Fixed Switching Period Discrete-time Sliding Mode Current Control of a PMSM. IEEE Trans. Ind. Electron. 2018, 65, 2039-2048. [CrossRef]

13. Mohd Zaihidee, F.; Mekhilef, S.; Mubin, M. Robust Speed Control of PMSM Using Sliding Mode Control (SMC)—A Review. Energies 2019, 12, 1669. [CrossRef]

14. Dendouga, A. Conventional and Second Order Sliding Mode Control of Permanent Magnet Synchronous Motor Fed by Direct Matrix Converter: Comparative Study. Energies 2020, 13, 5093. [CrossRef]

15. Usama, M.; Kim, J. Low-Speed Transient and Steady-State Performance Analysis of IPMSM for Nonlinear Speed Regulator with Effective Compensation Scheme. Energies 2021, 14, 6679. [CrossRef]

16. Mu, C.; He, H. Dynamic Behavior of Terminal Sliding Mode Control. IEEE Trans. Ind. Electron. 2018, 65, 3480-3490. [CrossRef]

17. Sun, X.D.; Cao, J.; Lei, G.; Guo, Y.G.; Zhu, J.G. A Composite Sliding Mode Control for SPMSM Drives Based on a New Hybrid Reaching Law with Disturbance Compensation. IEEE Trans. Transp. Electrif. 2021, 7, 1427-1436. [CrossRef]

18. Junejo, A.K.; Xu, W.; Mu, C.; Ismail, M.M.; Liu, Y. Adaptive Speed Control of PMSM Drive System Based a New Sliding-Mode Reaching Law. IEEE Trans. Power Electron. 2020, 35, 12110-12121. [CrossRef]

19. Wu, S.; Su, X.; Wang, K. Time-Dependent Global Nonsingular Fixed-Time Terminal Sliding Mode Control-Based Speed Tracking of Permanent Magnet Synchronous Motor. IEEE Access 2020, 8, 186408-186420. [CrossRef]

20. Valenciaga, F.; Puleston, P.F.; Battaiotto, P.E. Variable Structure System Control Design Method Based on a Differential Geometric Approach: Application to a Wind Energy Conversion Subsystem. IEE Proc.-Control Theory Appl. 2004, 151, 6-12. [CrossRef]

21. Lin, J.; Zhao, Y.; Zhang, P.; Wang, J.; Su, H. Research on Compound Sliding Mode Control of a Permanent Magnet Synchronous Motor in Electromechanical Actuators. Energies 2021, 14, 7293. [CrossRef]

22. Gong, Z.J.; Zhang, C.N.; Ba, X.; Guo, Y.G. Improved Deadbeat Predictive Current Control of Permanent Magnet Synchronous Motor Using a Novel Stator Current and Disturbance Observer. IEEE Access 2021, 9, 142815-142826. [CrossRef]

23. Xu, B.; Zhang, L.; Ji, W. Improved non-singular fast terminal sliding mode control with disturbance observer for PMSM drives. IEEE Trans. Transp. Electrif. 2021, 7, 2753-2762. [CrossRef] 
24. Sun, X.; Wu, J.; Lei, G.; Guo, Y.G.; Zhu, J.G. Torque Ripple Reduction of SRM Drive Using Improved Direct Torque Control with Sliding Mode Controller and Observer. IEEE Trans. Ind. Electron. 2021, 68, 9334-9345. [CrossRef]

25. Song, Q.; Li, Y.; Jia, C. A Novel Direct Torque Control Method Based on Asymmetric Boundary Layer Sliding Mode Control for PMSM. Energies 2018, 11, 657. [CrossRef]

26. Huang, M.; Deng, Y.; Li, H.; Shao, M.; Liu, J. Integrated Uncertainty/Disturbance Suppression Based on Improved Adaptive Sliding Mode Controller for PMSM Drives. Energies 2021, 14, 6538. [CrossRef]

27. Liu, J.; Li, H.; Deng, Y. Torque Ripple Minimization of PMSM Based on Robust ILC Via Adaptive Sliding Mode Control. IEEE Trans. Power Electron. 2018, 33, 3655-3671. [CrossRef]

28. Yu, S.; Yu, X.; Stonier, R. Continuous Finite-time Control for Robotic Manipulators with Terminal Sliding Modes. In Proceedings of the Sixth International Conference of Information Fusion, Cairns, Australia, 8-11 July 2003.

29. Krishnan, R. Permanent Magnet Synchronous and Brushless DC Motor Drives; CRC Pres: Boca Raton, FL, USA, 2009 ; pp. 288-290. 